distances and stay away from home as before. I suggest that specialist societies should urgently consider amalgamation or combined meetings with the larger organisations. Unless something is done to reduce expenses I feel sure that resignations will inevitably follow non-attendance and many of these valuable professional activities will cease. Little help can be expected from employing authorities, whose funds are wholly insufficient to cover meeting expenses for most of their staff.

Department of Histopathology, Southampton

R A Goodbody

Phenylbutazone, oxyphenbutazone and aplastic anaemia

SIR,-Dr W H W Inman's study on fatal bone marrow depression with special reference to phenylbutazone and oxyphenbutazone (11 June, p 1500) is interesting and important. It provides confirmatory evidence that phenylbutazone and oxyphenbutazone are now the drugs most often found as the cause of druginduced aplastic anaemia and that in that respect they, at least in countries like Britain, Australia, and Sweden, have replaced chloramphenicol. A conference in Kyoto in the autumn of 1976, however, clearly demonstrated that in the Far East, for example, the latter drug was still frequently used and a common cause of fatal bone marrow depression.

The mortality figures reported by Dr Inman are virtually identical with those reported by myself. ${ }^{2}$ I found figures for phenylbutazone and oxyphenbutazone, together, of 1-3 cases per 100000 . Furthermore, my figures clearly -like Dr Inman's-demonstrate the dominating role played by age, not only for aplastic anaemia, but for drug-induced cytopenias of all types. Thus special caution should be used in all medication given to elderly patients, especially with drugs known to be potential bone-marrow depressants, like phenylbutazone and oxyphenbutazone.

Department of Medicine,

L E BötTIGER Karolinska Hospital, Stockholm, Sweden

Böttiger, L E, and Westerholm, B, Acta Medica Scandinavica, 1972, 192, 315 .

Böttiger, L E, and Westerholm, B, British Medical fournal, 1973, 3, 339.

\section{Making better use of our nurses}

SIR,-Your leading article on this subject (21 May, p 1306) raises a number of points which are relevant to the organisation of primary medical care.

In primary medical care it is the usual practice for a patient to consult the general practitioner first, whatever the problem, and for the GP to refer the patient if appropriate to the nurse or elsewhere. This tends to perpetuate the nurse's "handmaiden" role both in the patient's eyes and in the eyes of the GP.

Although an expansion of the nurse's role to include primary consultation and decisionmaking has been permitted in some areas, it is by no means the rule. The possibility was explored recently in this locality but was rejected by those in authority, mainly on the basis of idiosyncratic decisions regarding what was "doctor's work" and what was "nurse's work." For example, it was agreed that ear syringing could be nurse's work but not venepuncture, that nurses could administer cyanocobolamin but not cholera vaccine, that nurses could use a vitalograph but not an ECG. In no case would they be allowed to make a diagnostic decision (even though training was offered)

Two practical and legal obstacles to nurses taking on more clinical commitments within the NHS seem to be, firstly, that the GP has a legal contract with the family practitioner committee for this purpose and not the nurse (except in a delegated role), and secondly, the nurse's inability to prescribe even a limited range of drugs on FP10.

If, as I believe, the GP should endeavour to fulfil the role of our late colleague the general physician he will need more than an average $6 \frac{1}{2}$ minutes' consultation. A longer average consultation-time will entail either longer working hours or delegating more work to others, especially nurses, for both first-time assessment and follow-up consultations.

Certainly experiment is needed. There are grounds for believing that such experiment would be welcomed by many nurses, but the resistance of those in authority over them needs to be overcome. Maybe it would be helpful if the Department of Health and Social Security were to let it be known that they would not look askance on any properly designed proposal.

Department of General Practice.

H W K ACHESON

Department of General P
Universitv of Manchester

Maintenance digoxin after an episode of heart failure

SIR,-Dr Sylvia $M$ Dobbs and her colleagues (19 March, p 749) claim that their findings show the value of digoxin in the maintenance treatment of heart failure apart from the control of atrial fibrillation, but the data presented are inadequate for this conclusion. In particular, the composition of the groups of patients makes the results difficult to interpret. Thirteen of the 46 patients studied were in atrial fibrillation, but none of the 13 had a history of a ventricular rate greater than $120 / \mathrm{min}$. Since all had been treated for heart failure it is remarkable that none had ever had heart rates faster than this; perhaps all 13 were "slow fibrillators," incapable of faster rates and at risk of serious bradycardia on digoxin. The number of patients with atrial fibrillation in the group who relapsed on placebo is not stated; it is not enough merely to say that there is no significant difference in cardiac rhythm between the groups, especially since the level of significance is not mentioned. With groups of 16 and 30 patients important differences in composition might fail to reach statistical significance at the $5 \%$ level.

The inclusion of 10 patients with cor pulmonale makes the interpretation of radiographic and spirometric data difficult. The mean values of $\mathrm{FEV}_{1}$ and FVC were remarkably low, especially in the group who relapsed on placebo.

The authors suggest that shortening of left ventricular ejection time index (LVETI) after treatment with digoxin for one month is evidence for a continuing inotropic response to the drug. However, there is no indication whether the systolic time interval (STI) was measured under standardised conditions. LVETI is particularly susceptible to many influences other than inotropic effect, including ventricular volume, pre-load, peripheral re- sistance, level of adrenergic stimulation, and time of day ${ }^{1-3}$ Furthermore, the STIs recorded while the patients were taking placebo were not significantly different from those of normal subjects, which is in contrast with the findings of Weissler et $\mathrm{al}^{4}$; this suggests that the patients in this part of the study may have had especially mild heart failure. Weissler et $a l^{1}$ showed that pre-ejection period index (PEPI) was a more consistent indicator of inotropic effect than LVETI, but in the patients of Dr Dobbs and her colleagues PEPI did not change on digoxin therapy. Finally, any uncontrolled haemodynamic observations made at intervals as great as one month must be regarded with the greatest suspicion.

\section{S J WARRINGTON} N A J HAMER

Department of Clinical

Pharmacology,

St Bartholomew's Hospital,

London ECl

' Weissler, A M, and Schoenfeld, C D, American fournal of Medical Sciences, 1970, 259, 4

Lewis, R P, et al, American fournal of Cardiology,

1976, 37, 787.
Weissler, A M, et al, American fournal of Cardiology,

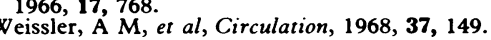

\section{Health visitors and child health}

SIR,-I have read with interest "Has the Court Report been misunderstood ?" (11 June, p 1522) and I would like to make one comment and ask one question.

Vocational training is necessary for all doctors, but for those thinking of general practice it is essential. It is not enough to make a diagnosis and prescribe the correct course of treatment without fully understanding the causative social factors. It is less than useless to prescribe a daily bath for someone without hot water.

The question I would ask is, does Professor Court really think that the work in Sheffield has been carried out by health visitors without cost? I am pleased to hear that they have improved the statistics on child health without any increase in numbers, but as a health visitor myself I would guess that many other aspects of work have of necessity been abandoned to enable them to give enough time to this work.

The health visitor has been trained as a family visitor and while every health visitor in the country would, I am sure, agree that child health has to be a priority, it would be stupid and very wrong to assume that that is the only work requiring attention. Middle-aged people have great problems and elderly people have too many problems to mention in this letter. If we do not give the right level of care to preventing some of these problems we will have too many elderly in hospital beds and the child will have difficulty in gaining admission for the removal of its appendix.

I hope the health visitors in Sheffield will be able to afford a little time away from child assessments to inform Professor Court about some of their other duties. Time given to one aspect of community care is time taken away from another.

Health visitors want to continue to promote child health to its highest level, but it has to be understood that there is a cost involved. Unless there is a great increase in the number of health visitors there will inevitably be less time to give to other work. A lot of health visitors view this 